\title{
Free Trade vs. Autarky under Asymmetric Cournot Oligopoly
}

\author{
Rabah Amir* \\ University of Iowa \\ Jim Y. Jin ${ }^{* *}$ \\ University of St Andrews \\ Michael Tröge ${ }^{* * *}$ \\ ESCP-Europe
}

JEL Classification Number: F12, F15, D43

Key Words: free trade, Cournot competition, welfare loss

July 2016

\begin{abstract}
The paper compares free trade with autarky in an asymmetric multi-country world with Cournot competition, constant returns to scale and linear demand. We derive conditions under which free trade will hurt a country's consumers, benefit its firms, induce it to export, increase its output, and raise its welfare. We show that these conditions are linked in a clear order, with one implying the next. We further demonstrate that free trade can reduce world total output and total consumer surplus as well as world welfare. Along the way, we correct several oversights in the literature.
\end{abstract}

\footnotetext{
* Department of Economics, University of Iowa, Iowa City, IA 52242, U.S.A. E-mail: rabah-amir@uiowa.edu. ** School of Economics and Finance, University of St Andrews, St Andrews KY16 9AL, UK, e-mail: jyj@standrews.ac.uk.

Correspondant author: ESCP Europe, 97 av. de la République, 75543 Paris Cedex, France, e-mail: troege@escpeurope.eu

We would like to thank Arnaud Costinot, Vanessa Strauss-Kahn and seminar participants at Université Paris I Panthéon Sorbonne for helpful discussions and comments.
} 


\section{Introduction}

This paper examines the effects of free trade compared to autarky in the classic partial equilibrium Cournot model with linear demand and cost functions, a fixed number of firms with no trade costs. As aptly observed by Helpman and Krugman (1985, p. 88), in this setting, "the direction of trade cannot, as in a purely competitive model, be determined simply by a comparison of costs or of pre-trade prices. There are three sets of variables here - costs, market sizes, and numbers of firms - and all must be taken into account."

Starting with Helpman and Krugman (1985), the literature has identified conditions under which trade affects a country, such as increasing consumer surplus, increasing profits, inducing the country to export or import, increasing production or welfare. A number of papers have also demonstrated that these effects are inter-connected. For example, Markusen (1981), Cordella (1993) and Dong and Yuan (2010) (D\&Y) use two-country models to show that a country's welfare can fall under free trade only if it imports the oligopoly good and consumers can be worse off only if firms are better off. However, the literature has not identified general conditions in an asymmetric world with more than two countries.

Our first objective is to extend the earlier findings and provide simple conditions for these effects of trade and their relations. In particular, we show that there is a clear ranking among these conditions: If free trade hurts a country's consumers, it must benefit its firms. If trade benefits a country's firms, the country must export and this, in turn, implies that its total output rises. Finally, if a country's total output rises, so does its social welfare.

The second goal of this paper is to investigate the possibility for free trade to lower world welfare, total consumer surplus and output in a simple linear Cournot model. It is well known that there exist special situations where trade has undesirable effects ${ }^{1}$ and D\&Y recently derived

\footnotetext{
${ }^{1}$ The insight that trade can harm individual countries goes back to Bhagwati (1971) and Johnson (1965). Situations where trade can reduce world welfare include: inefficient specialization (Krugman 1979, Markusen 1981, Eckel 
a necessary and sufficient condition for free trade to lower total welfare with two countries. Their analysis, however, contains several oversights. We clarify these errors and demonstrate that, in a more general model, trade may reduce not only world welfare, but also world output and consumer surplus.

\section{Model}

There are $m(\geq 2)$ countries. Every country $i$ has a representative consumer with a quadratic utility function $z_{i}+a_{i} y_{i}-0.5 b_{i} y_{i}^{2}$, where $z_{i}$ is the numeraire good and $y_{i}$ is the consumption of the oligopoly good. Utility maximization implies an inverse demand function $p_{i}=a_{i}-b_{i} y_{i}$. There are $n_{i}(\geq 1)$ firms in each country that have identical and constant marginal $\operatorname{cost} c_{i}<a_{i}$. In the Cournot equilibrium, every firm chooses its output $q_{i}$ to maximize its profit $\left(p_{i}-c_{i}\right) q_{i}$. Under autarky, the first-order condition $p_{i}-c_{i}-b_{i} q_{i}=0$ yields the equilibrium price: $p_{i}^{A}=\frac{a_{i}+n_{i} c_{i}}{n_{i}+1}$. A country's autarky output must be equal to its consumption, so we have $n_{i} q_{i}^{A}=y_{i}^{A}=\frac{n_{i}\left(a_{i}-c_{i}\right)}{b_{i}\left(n_{i}+1\right)}$.

Under free trade, there is a single world price of $p^{T}$. Given $p^{T}$, country $i$ 's demand will be $y_{i}^{T}=\left(a_{i}-p^{T}\right) / b_{i}$ and the world total demand $y^{\mathrm{T}} \equiv \sum_{i=1}^{m} y_{i}^{T}=\sum_{i=1}^{m} \frac{a_{i}-p^{T}}{b_{i}}$. Using $\beta \equiv \sum_{i=1}^{m} 1 / b_{i}$ to indicate the size of the world market, we can write the equilibrium price under free trade as $p^{\mathrm{T}}=\frac{1}{\beta}\left(\sum_{i=1}^{m} \frac{a_{i}}{b_{i}}-y^{\mathrm{T}}\right)$. When every firm in country $i$ maximizes its profit $\left(p^{\mathrm{T}}-c_{i}\right) q_{i}$, the firstorder condition is $p^{T}-c_{i}-q_{i} / \beta=0$. A firm's optimal output is $q_{i}^{T}=\beta\left(p^{T}-c_{i}\right)$ and the world

2008), segmented markets and transportation costs (Brander and Krugman 1983), the absence of insurance markets (Newbery and Stiglitz 1984), strongly increasing returns and non-linear demand (Markusen and Melvin 1988), firms' location choice (Eaton and Kierzkowski 1984), increasing dispersion of markups (Epifani and Gancia 2011). None of these effects are present in our model. 
total output and total consumption $y^{T}=\sum_{i=1}^{m} n_{i} q_{i}^{T}$. We denote the total number of firms by $N \equiv$ $\sum_{i=1}^{m} n_{i}$. The free trade equilibrium price can be solved as:

$$
p^{\mathrm{T}}=\frac{1}{N+1} \sum_{i=1}^{m}\left(\frac{a_{i}}{\beta b_{i}}+n_{i} c_{i}\right)
$$

We assume min. $\left\{a_{i}\right\} \geq p^{\mathrm{T}} \geq \max .\left\{c_{i}\right\}$, to guarantee that consumers and firms in all countries are active in the market under free trade. Country $i$ 's consumer surplus $C S_{i}=a_{i} y_{i}-$ $0.5 b_{i} y_{i}^{2}-p_{i} y_{i}=0.5\left(a_{i}-p_{i}\right)^{2} / b_{i}$, firms' total profit $\pi_{i}=n_{i} q_{i}\left(p_{i}-c_{i}\right)$ and social welfare $S W_{i}=0.5\left(a_{i}-p_{i}\right)^{2} / b_{i}+n_{i} q_{i}\left(p_{i}-c_{i}\right)$. The respective values can be found by substituting $p_{i}$ and $q_{i}$ under free trade and autarky, as solved above (details are left out).

Next, we investigate the effects of free trade on individual countries.

\section{The Effects of Trade}

In this section, we consider the effects of trade on a country's welfare, consumer surplus, profits, trade position and output. A key variable that will help us simplify mathematical expressions is the ratio of the price margin under autarky over the margin under free trade, i.e., $\left(p_{i}^{A}-c_{i}\right) /\left(p^{\mathrm{T}}-c_{i}\right)$. We denote this ratio for country $i$ by $d_{i}$.

The value of $d_{i}$ depends on the model's primitives, specifically on the average cost and reservation price. Using (1) we can express the price margin under free trade, $p^{T}-c_{i}$ as the sum of $\sum_{j=1}^{m} \frac{a_{j}}{\beta b_{j}}-c_{i}$ and $\sum_{j=1}^{m} n_{j}\left(c_{j}-c_{i}\right)$ divided by $N+1$. The price margin under autarky $p_{i}^{A}-c_{i}$ can be viewed as a special case of this expression with only one country $i$. If $c_{i}$ is equal to the average cost $\sum_{j=1}^{m} n_{j} c_{j} / N$, the second term of $p^{T}-c_{i}$ disappears. Similarly, the first term 
reduces to $a_{i}-c_{i}$ if $a_{i}$ is equal to $\sum_{j=1}^{m} \frac{a_{j}}{\beta b_{j}}$, which can be interpreted as the world's (size weighted) average reservation price, as $\sum_{j=1}^{m} \frac{1}{\beta b_{j}}=1$. Hence, if a country's reservation price and cost are equal to the world average, we have $d_{i}=(N+1) /\left(n_{i}+1\right)>1$, implying the price change caused by trade only depends on the numbers of firms in country $i$ and in the world. If $c_{i}$ is lower than the average cost, or if $a_{i}$ is lower than the average reservation price, $d_{i}$ will be smaller than this value, as less efficient foreign firms and higher foreign demand weaken competition. When $c_{i}$ and $a_{i}$ are sufficiently low, $d_{i}$ can be lower than 1 , implying a higher price under free trade. Next we use $d_{i}$ to express various conditions for free trade to benefit or harm a country's consumers, firms and its welfare etc.

(i) Consumer surplus: Consumers gain if and only if free trade decreases the price, i.e., $p^{\mathrm{T}}<p_{i}^{A}$, or $d_{i}>1$. The value of $d_{i}$ depends on all parameters in this model through $p^{\mathrm{T}}$. However, we can obtain a sufficient condition for $d_{i}>1$, which only depends on a country's reservation price $a_{i}$, and the world average reservation price $\sum_{j=1}^{m} \frac{a_{j}}{\beta b_{j}}$. So we have a sufficient condition for free trade to benefit a country's consumers (see Appendix I).

Proposition 1: Free trade benefits a country's consumers if its reservation price is not lower than the world average reservation price.

The literature (e.g. D\&Y) often assumes $a_{i}=a$, for every country $i$, which guarantees our condition in the proposition. Hence, if all countries have the same reservation price, all consumers are better off under free trade than under autarky. Usually, however, consumers in rich countries tend to have higher reservation prices and are therefore more likely to benefit from trade than their counterparts from poor countries. 
(ii) Profit: Intuitively, the interests of firms and consumers regarding trade are not necessarily aligned. When producers suffer from imported goods, consumers usually benefit. Likewise, if high export demand increases prices, consumers will suffer, but firms generate high profits. To obtain conditions under which firms benefit from trade, we compare their profit under free trade, $\left(p^{\mathrm{T}}-c_{i}\right) q_{i}^{T}=\beta\left(p^{\mathrm{T}}-c_{i}\right)^{2}$, with their profit under autarky, i.e. $\left(p_{i}^{A}-c_{i}\right) q_{i}^{A}=\left(a_{i}-c_{i}\right)^{2} /($ $\left.n_{i}+1\right)^{2} b_{i}$. Clearly, the former is larger than the latter if and only if $\sqrt{\beta b_{i}}\left(p^{\mathrm{T}}-c_{i}\right)>\left(a_{i}-c_{i}\right) /($ $\left.n_{i}+1\right)$, or $d_{i}<\sqrt{\beta b_{i}}$. Hence, we have:

Proposition 2: Free trade benefits country i's firms if and only if $d_{i}<\sqrt{\beta b_{i}}$.

Since $\sqrt{\beta b_{i}}>1$, it is impossible to have $d_{i}<1$ and $d_{i}>\sqrt{\beta b_{i}}$ simultaneously. Hence the consumers and firms of any country cannot both be worse off. Furthermore, as $d_{i}<1$ implies $d_{i}$ $<\sqrt{\beta b_{i}}$, a reduction in consumer surplus implies an increase in profits. Likewise, as $d_{i}>\sqrt{\beta b_{i}}$ implies $d_{i}>1$, lower profits mean higher consumer surplus. Note, that for firms' profits to increase, $p^{T}$ need not be higher than $p_{i}^{A}$. As the price under free trade is less sensitive to a firm's output than under autarky $\left(\beta>1 / b_{i}\right)$, a firm produces more even if prices do not change. So it is better off as long as $p^{T}$ is not too much lower than $p_{i}^{A}$. The larger the relative increase in market size indicated by $\beta b_{i}$, the lower $p^{\mathrm{T}}$ can be without making the firms worse off.

(iii) Export/Import: In a two-country model such as D\&Y, one country must export and the other import under free trade, but this relation may change in a multi-country setting as now one country's export need not correspond to any other country's import. To find out if a country exports under free trade, we have to compare its output $n_{i} q_{i}^{T}=\beta n_{i}\left(p^{T}-c_{i}\right)$ to its consumption, 
$y_{i}^{T}=\left(a_{i}-p^{\mathrm{T}}\right) / b_{i}$, i.e., to check whether $\beta n_{i}\left(p^{\mathrm{T}}-c_{i}\right)>\left(a_{i}-p^{\mathrm{T}}\right) / b_{i}$. This inequality is equivalent to $\left(\beta b_{i} n_{i}+1\right)\left(p^{\mathrm{T}}-c_{i}\right)>a_{i}-c_{i}$. Hence, we have:

Proposition 3: A country exports if and only if $d_{i}<\frac{1+\beta b_{i} n_{i}}{1+n_{i}}$.

It is easy to see that $d_{i}<\sqrt{\beta b_{i}}$ implies $d_{i}<\left(1+\beta b_{i} n_{i}\right) /\left(1+n_{i}\right)$. So, if a country has higher profits under free trade, it must export, but the reverse is not necessarily true. Common sense seems to suggest the opposite: an exporting country should generate higher profits under free trade. In fact, a country is more likely to export than to earn higher profits, because free trade generally depresses prices even if it increases demand.

(iv) Output: Free trade generally stimulates production, because firms know that an increase in their output has a less negative impact on the price and will consequently produce more, given the same price. However, as D\&Y have shown, it is possible that a low cost country ends up producing less, due to an excessive output expansion by a high cost country. A rise in country $i^{\text {'s }}$ production requires that every firm's output under free trade $q_{i}^{T}=\beta\left(p^{T}-c_{i}\right)$ exceeds that under autarky, $\left(a_{i}-c_{i}\right) / b_{i}\left(n_{i}+1\right)$. Comparing these two terms we obtain:

Proposition 4: A country's output rises under free trade if and only if $d_{i}<\beta b_{i}$.

Note that $\beta b_{i}>\left(1+\beta b_{i} n_{i}\right) /\left(1+n_{i}\right)$ always holds. So if a country exports, i.e. $d_{i}<\left(1+\beta b_{i} n_{i}\right) /\left(1+n_{i}\right)$, we have $d_{i}<\beta b_{i}$, i.e. its output must rise.

(v) Social Welfare: Since firms and consumers cannot both lose under free trade, a country's welfare may fall either if its firms' loss exceeds its consumers' gain, or if its firms' gains are lower that its loss in consumers surplus. Interestingly, we will show that the latter is impossible: A welfare loss can occur only when firms lose and consumers gain. We find that free 
trade always benefits a country as a whole if $\Delta_{i} \equiv n_{i}+2-2 \beta b_{i}<0$. If the country has few firms, consumers are likely to benefit from trade. If the world market is much larger than the home market (high $\beta b_{i}$ ), firms are likely to gain. So firms' loss cannot exceed consumers' gain. When this condition fails, welfare can fall when $d_{i}$ is sufficiently close to $1+n_{i}$. We can obtain a necessary and sufficient condition for a country's welfare loss (see Appendix II):

Proposition 5: Free trade reduces a country's welfare if and only if $\Delta_{i} \equiv n_{i}+2-2 \beta b_{i}$ $>0$ and $1+n_{i}-\sqrt{n_{i} \Delta_{i}}<d_{i}<1+n_{i}+\sqrt{n_{i} \Delta_{i}}$.

Note $1+n_{i}-\sqrt{n_{i} \Delta_{i}}>\beta b_{i}$ always. So a country's welfare can fall only if $d_{i}>\beta b_{i}$, implying its output reduction, importing, profit falling and consumer surplus rising. This result also indicates the trade-off between consumers' gain and firms' loss. If $d_{i}<1$ we have $p^{T}>p_{i}^{A}$, consumers lose and firms gain. Welfare must rise as $n_{i}>\sqrt{n_{i} \Delta_{i}}$. When $\sqrt{\beta b_{i}}>d_{i}>1$ both consumers and firms gain, so welfare rises too. When $d_{i}>\sqrt{\beta b_{i}}$, free trade benefits consumers but hurts firms. As $d_{i}$ rises further to meet the first inequality in Proposition 5, consumers' gain is equal to firms' loss, and welfare does not change. For an even higher $d_{i}$ the welfare falls under free trade until the $2^{\text {nd }}$ inequality is met. Beyond this point a higher $d_{i}$ will guarantee that consumers' gain dominates firms' loss, implying a higher welfare under free trade. Hence, a welfare loss cannot happen if $d_{i}$ is either too high or too low. If $d_{i}$ is very high, $p^{\mathrm{T}}$ is relatively low and the consumers' gain will dominate any profit loss. If $d_{i}$ is very low, $p^{\mathrm{T}}$ is relatively high and firms cannot lose enough to offset consumers' gain.

(vi) Relations between Conditions: In the discussion above, we have already characterized relations between pairs of conditions. Simply by linking these pairwise connections we can establish a clear ordering: 
Proposition 6: If a country's consumers are worse off under free trade, its firms must be better off. If profits increase, the country must export, which implies that its output must increase. Finally a higher output guarantees a welfare gain for this country.

Conversely, we easily see that, if a country's social welfare falls under free trade, its output must fall, which implies that the country is an importer. This in turn means profits fall, which implies that consumer surplus must increase.

To get some intuition for these relationships, Figure 1 shows how a low cost country 1 is affected when trading with a high cost country 2 . The indifference curves show for which combinations of country 1 's reservation price $a_{1}$ and the number of firms $n_{1}$, its welfare, production, trade position, profits and consumer surplus remain unaffected. We also add the indifference curve for the sum of both countries' welfare which indicates the possibility of a world welfare loss.

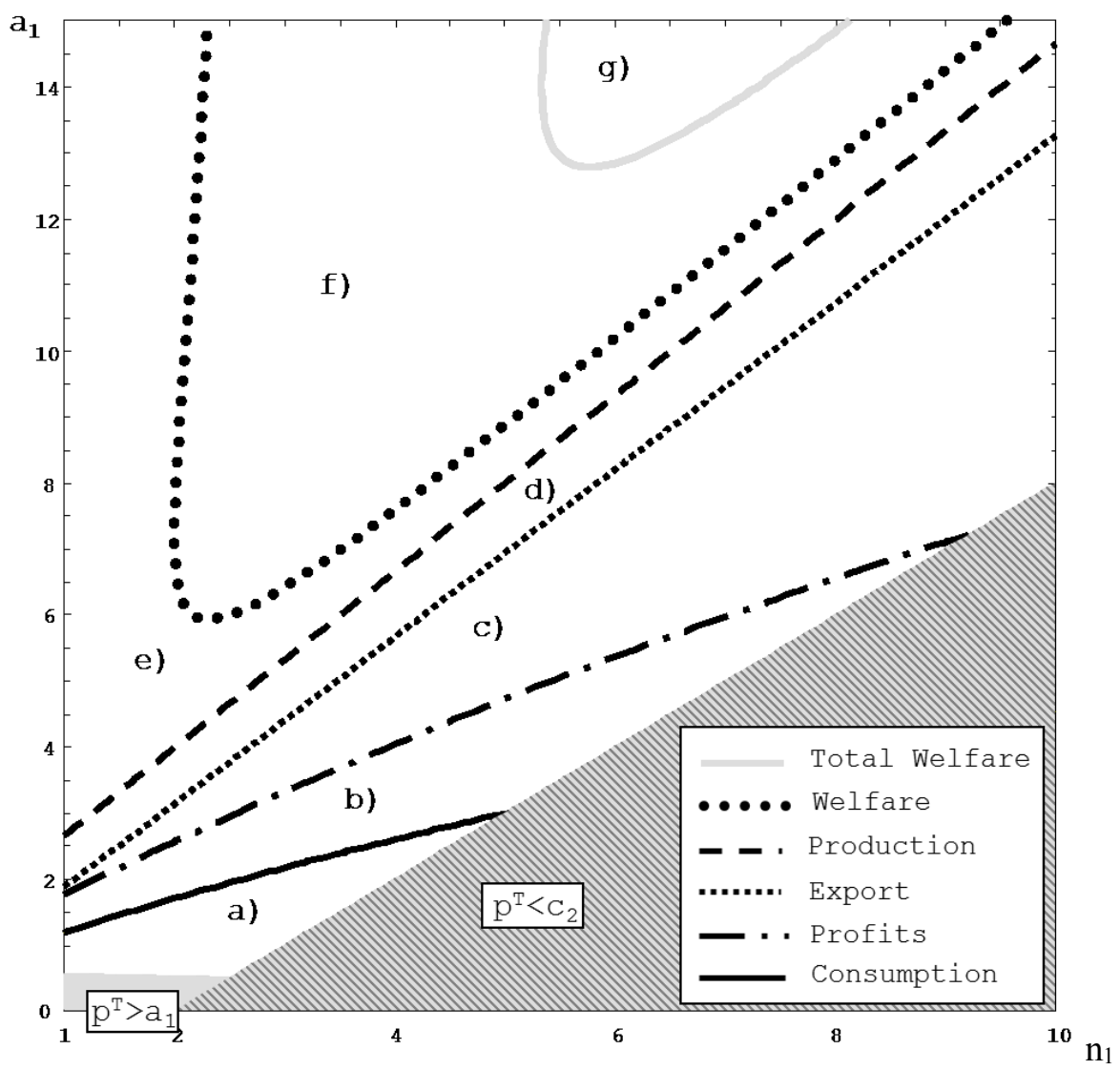


Figure 1: Indifference curves for country 1's consumers, firms, export, production and welfare given $a_{2}=3, b_{1}=b_{2}=1, n_{2}=9, c_{1}=0, c_{2}=0.5$

In the grey areas at the bottom of this graph, under free trade some firms or consumers exit the market, which violates our assumptions. In region a), with very low $a_{1}, p_{1}^{A}$ is lower than $p^{\mathrm{T}}$, implying a loss of consumer surplus. In region $\mathrm{b}$ ), with higher $a_{1}$, trade reduces prices so consumers are better off. A further increase of $a_{1}$ leads to region c), where firms are worse off, as they lose the high profits they would made under autarky. As $a_{1}$ continues to rise, we enter region d), where the large domestic market starts to attract foreign goods and turns country 1 to an importer. The next region e) has a higher $a_{1}$. Now imports force domestic firms to reduce production, despite having lower costs. All indifference curves are upward sloping. This is because with higher $n_{1}$, the domestic market is more competitive, and less affected by country 2's high cost producers. We therefore need more of an increase in $a_{1}$ to move from one region to another. Finally, if $n_{1}>2$ and $a_{1}$ further rises we enter region f), where country 1's welfare decreases.

For most parameter values we still find that trade increases consumer surplus, decreases profits and raise welfare (regions $(\mathrm{c})+(\mathrm{d})+(\mathrm{e}))$. However, the range of parameter constellations for welfare decrease is surprisingly large (region (f)).

\section{Inefficient Trade}

The above analysis provides some clues for understanding how trade can lead to a reduction of world welfare. In the example presented in Figure 1, the inefficient country 2 will always benefit from trade. However, if country 1 is sufficiently large and has sufficient, but not too many firms, its welfare loss may exceed country 2's welfare gain. This will lead to a decrease of world welfare as shown by region g). Essentially, in this case, opening trade is equivalent to the entry of country 2's inefficient firms in country 1's market. We know from Lahiri and Ono 
(1988) that under Cournot competition this can reduce total welfare. Unfortunately, it is algebraically very cumbersome to provide the precise conditions for this to happen. To our knowledge D\&Y are the first to have carried out this analysis in a linear Cournot model. However, their result suffers from a few small errors that need clarification.

D\&Y's model is a special case of our setup with two countries and identical reservation prices. They assume demand functions $y_{1}=a-b p_{1}$, and $y_{2}=\chi\left(a-b p_{2}\right)$, where $\gamma(\geq 0)$ is the relative size of the two countries' demand. To simplify their formulae and avoid confusion with our parameters $b_{i}$, we set their parameter $b=1$, without loss of generality. We can then write the inverse demand functions as $p_{1}=a-y_{1}$, and $p_{2}=a-y_{2} / \gamma$. D\&Y assume the marginal cost in country 1 ("Southern") to be higher than in country 2 ("Northern"), i.e. $c_{1}>c_{2}$. They argue that a necessary condition for a decrease in world welfare is "the displacement of production of the northern country by that of the southern country" (p. 826). Their Proposition 1 gives a sufficient condition for country 2's output reduction:

$$
\frac{a-c_{2}}{c_{1}-c_{2}}>\frac{n_{2}\left(n_{2}+1\right)(1+\gamma)}{m_{1}-n_{2}-1}
$$

This condition is incorrect. If the two countries have the same size $(\gamma=1)$ and the same number of firms $\left(n_{1}=n_{2}\right),(2)$ holds, but in this case the low cost country 2's output should increase. The correct condition can be derived from our Proposition 4, which states that country 2's output falls if and only if $\beta b_{2}<d_{2}$. Using D\&Y's parameter $\gamma$, which corresponds to $b_{1} / b_{2}$ in our notation, we have $\beta b_{2}=1+1 / \gamma$. Then as $p_{2}^{A}-c_{2}=\frac{a_{2}-c_{2}}{n_{2}+1}$ and $p^{\mathrm{T}}-c_{2}=$ $\frac{a-c_{2}+n_{1}\left(c_{1}-c_{2}\right)}{n_{1}+n_{2}+1}, \beta b_{2}<d_{2}$ holds if and only if

$$
\left(\gamma n_{1}-1-n_{2}\right)\left(a-c_{2}\right)>(1+\gamma)\left(1+n_{2}\right) n_{1}\left(c_{1}-c_{2}\right)
$$


When dividing (3) by $c_{1}-c_{2}$ and $\gamma n_{1}-1-n_{2}$, D\&Y apparently ignore the possibility that a negative sign might reverse the direction of the inequality. In addition their $n_{2}$ on the right hand side should be $n_{1}$. This error seems to lead to a follow-up mistake. D\&Y claim in their Proposition 7 that free trade reduces total welfare if $c_{2}$ is higher than a threshold $c_{2}^{* *}$ and country 2's size $\gamma$ is sufficiently small. However, their $c_{2}^{* *}$ is defined, in our notation, as:

$$
\mathrm{c}_{2}^{* *}=\frac{\left(2 n_{1}+n_{2}+2\right) a+c_{1}\left[2\left(n_{1}+1\right)^{2}\left(n_{1}+n_{2}+1\right)-\left(n_{1} n_{2}+2 n_{1}+2 n_{2}+2\right)\right]}{\left[2\left(n_{1}+1\right)^{2}+n_{2}\left(2 n_{1}+1\right)\right]\left(n_{1}+1\right)}
$$

This can be simplified to $c_{2}^{* *}=c_{1}+\frac{\left(2 n_{1}+n_{2}+2\right)\left(a-c_{1}\right)}{\left.\left(n_{1}+1\right)\right)\left[2\left(n_{1}+1\right)^{2}+n_{2}\left(2 n_{1}+1\right)\right]}$. Since $a>c_{1}$, we have $c_{2}^{* *}>c_{1}$. So the condition for total welfare loss, $c_{2}>c_{2}^{* *}$ violates their assumption that $c_{1}$ $>c_{2}$. However, if we assume $c_{2}>c_{1}$, D\&Y's Proposition 7 will be essentially correct, ${ }^{2}$ i.e. the total welfare falls due to free trade if $\frac{a+n_{1} c_{1}}{n_{1}+1}>c_{2}>c_{2}^{* *}$ and $\gamma$ is sufficiently small.

In line with the intuition discussed above, it can be shown that the maximum welfare loss in this D\&Y's two-country model occurs when $\gamma=0, n_{1}=1, n_{2}=$ infinity, i.e. when a very small country with a large number of inefficient firms trades with a large country with an efficient monopoly. The maximum welfare loss in this case is $1 / 9$ of the original total welfare, which is quite significant.

Furthermore, asymmetric demand intercepts in our model increase the scope for generating a total welfare loss compared to D\&Y's setup. Figure 1 shows a total welfare loss in region g), which does not require extreme parameter combinations and different country sizes.

\footnotetext{
2 There is another small error in the definition of DY's critical value $\gamma^{* *}=-D / F$. The term $a\left(2 n_{1}+n_{2}+2\right)$ in $F$ should be $a\left(2 n_{2}+n_{1}+2\right)$ instead.
} 
In the appendix we illustrate this with a simple numerical example with $a_{1}=14, n_{1}=6$, and $b_{1}=$ $b_{2}$ (i.e. $\gamma=1$ in $\mathrm{D} \& \mathrm{Y}^{\prime}$ 's notation), as a point in region $(\mathrm{g})$.

Asymmetric demand intercepts also lead to another surprising result. In D\&Y's model trade will always increase total output and every country's consumer surplus. This is a direct consequence of our Proposition 1, as in their model both countries have identical reservation prices. If this restriction is relaxed, we can find parameter constellations for which trade decreases world consumer surplus and total output.

We illustrate this possibility in Figure 2, representing the combinations of $a_{2}$ and $n_{2}$ for which world consumer surplus and/or world output decrease. In this case, consumers in country 1 lose as its efficient firms export, but the price in country 2 does not fall significantly, resulting in a decrease in total consumer surplus.

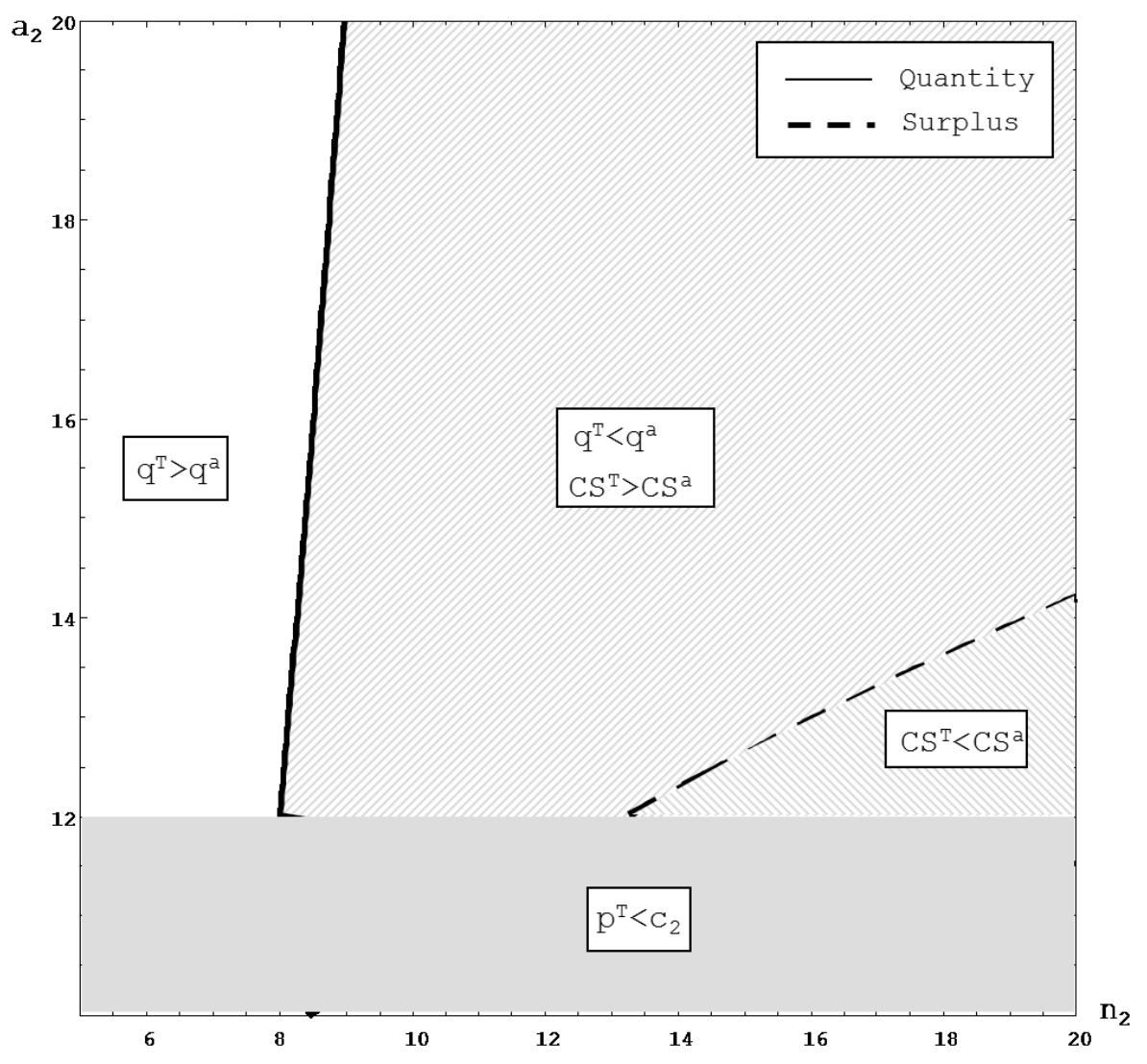

Figure 2: Reduction of world output and consumer surplus 


$$
a_{1}=9, b_{1}=b_{2}=1, n_{1}=1, c_{1}=0, c_{2}=5.25
$$

Interestingly, whereas world consumer surplus can fall only if world output falls, there is a large parameter space, where a decrease in output does not lead to a decrease in consumer surplus, as trade will allocate the smaller output more efficiently to consumers with high demand. Again we provide in the appendix a numerical example (with $a_{2}=12$ and $n_{2}=20$ ) where both total output and consumer surplus fall, as the right-bottom corner in Figure 2.

\section{Concluding remarks}

This paper analyzes an intra-industry trade model with imperfect competition between arbitrary numbers of asymmetric firms and countries. We first derive a set of conditions under which free trade with Cournot competition has a positive or negative impact on a country's consumers, firms, welfare, export/import position and output. We also provide a clear ranking for these conditions. In the second part of this paper, we clarify some oversights in D\&Y's analysis of welfare-reducing trade, and illustrate that, in a more general model, trade can also lead to a reduction in world output and total consumer surplus.

While theoretically interesting, we do not think, however, that our results should be viewed as a strong argument against free trade. Except in extreme cases, the magnitude of the total welfare loss is very small compared to the potential gains. 


\section{References:}

Bhagwati, J., 1971. The generalized theory of distortions and welfare. In: Bhagwati, J.,et al. (Ed.), Trade balance of payments and growth (Amsterdam: North-Holland).

Brander, J. and P. Krugman, 1983, A 'Reciprocal dumping' model of international trade, Journal of International Economics, 15 (3-4): 313-321.

Cordella, T., 1993, Trade Liberalization and Oligopolistic Industries: A Welfare Appraisal, Recherches Économiques de Louvain/Louvain Economic Review, 59 (3): 355-363.

Dong, B. and L. Yuan, 2010, The Loss from Trade under International Cournot Oligopoly with Cost Asymmetry, Review of International Economic Review, 18: 818-831.

Eaton, J. and H. Kierzowski, 1984, Oligopolistic Competition, Product Variety, and International Trade, in H. Kierzowski, eds) Monopolistic Competition and International Trade: 69-83, Clarendon Press, Oxford.

Eckel, C., 2008, Globalization and specialization, Journal of International Economics: 75 (1), 219-228.

Epifani, P., and G. Gancia, 2011, Trade, markup heterogeneity and misallocations, Journal of International Economics: 83 (1), 1-13.

Helpman, E. and P. Krugman, 1985, Market Structure and Foreign Trade, MIT Press, Cambridge.

Johnson, H.G., 1965, Optimal trade intervention in the presence of domestic distortions, In: Baldwin, R.E., et al. (Ed.), Trade, Growth and the Balance of Payments, Rand-McNally, Chicago.

Krugman, P., 1979, Increasing Returns, Monopolistic Competition, and International Trade, Journal of International Economics 9: 469-479.

Lahiri, S. and Y. Ono, 1988, Helping Minor Firms Reduces Welfare, Economic Journal, Royal Economic Society, 98 (393): 1199-1202.

Markusen, J., 1981, Trade and Gains from Trade with Imperfect Competition, Journal of International Economics 11: 531-551.

Markusen, J. and J. Melvin, 1988, the Theory of International Trade, Harper \& Row Publishers Inc.

Newbery, D. M. G. and J. E. Stiglitz, 1984, Pareto inferior trade, the Review of Economic Studies, 51 (1): $1-12$. 


\section{Appendix I, Proof of Proposition 1:}

Without loss of generality we assume $a_{1} \geq \sum_{i=1}^{m} \frac{a_{i}}{\beta b_{i}}$, and show $d_{1}>1$, i.e.

$$
\frac{1}{N+1}\left(\sum_{i=1}^{m} \frac{a_{i}}{\beta b_{i}}+\sum_{i=1}^{m} n_{i} c_{i}\right)<c_{1}+\frac{a_{1}-c_{1}}{1+n_{1}}
$$

(A1) holds if $\left(n_{1}+1\right)\left(a_{1}+\sum_{i=1}^{m} n_{i} c_{i}\right)<(N+1)\left(n_{1} c_{1}+a_{1}\right)$, i.e.

$$
a_{1}+n_{1} c_{1}>\frac{n_{1}+1}{N-n_{1}} \sum_{i=2}^{m} n_{i} c_{i}
$$

Let $\bar{c}=\max .\left\{c_{i}\right\}$. As $p^{\mathrm{T}}>\bar{c}$ and $a_{1} \geq \sum_{i=1}^{m} \frac{a_{i}}{\beta b_{i}}$, we have $a_{1}+\sum_{i=1}^{m} n_{i} c_{i}>(N+1) \bar{c}$, i.e. $a_{1}+$ $n_{1} c_{1}>(N+1) \bar{c}-\sum_{i=2}^{m} n_{i} c_{i}>\left(n_{1}+1\right) \bar{c}$. So (A2) must hold if $\left(n_{1}+1\right) \bar{c} \geq \frac{n_{1}+1}{N-n_{1}} \sum_{i=2}^{m} n_{i} c_{i}$, which is true as $\bar{c}=\max .\left\{c_{i}\right\}$. Hence (A1) must hold.

\section{Appendix II, Proof of Proposition 5:}

Country $i$ 's welfare under autarky is equal to $0.5\left(a_{i}-c_{i}\right)^{2}\left[1-1 /\left(1+n_{i}\right)^{2}\right] / b_{i}$. Under free trade, it is $0.5\left(a_{i}-p^{\mathrm{T}}\right)^{2} / b_{i}+\beta n_{i}\left(p^{\mathrm{T}}-c_{i}\right)^{2}$. The former is larger if and only if

$$
L \equiv\left(a_{i}-p^{\mathrm{T}}\right)^{2}+2 b_{i} \beta n_{i}\left(p^{\mathrm{T}}-c_{i}\right)^{2}-\left(a_{i}-c_{i}\right)^{2}\left[1-\frac{1}{\left(1+n_{i}\right)^{2}}\right]<0 .
$$

After re-arrangement, we get $\left(1+2 \beta b_{i} n_{i}\right)\left(p^{\mathrm{T}}-c_{i}\right)^{2}-2\left(a_{i}-c_{i}\right)\left(p^{\mathrm{T}}-c_{i}\right)+\frac{\left(a_{i}-c_{i}\right)^{2}}{\left(1+n_{i}\right)^{2}}<0$.

Dividing it by $\left(p^{\mathrm{T}}-c_{i}\right)^{2}$ and using the notation of $d_{i}$, we see that $L<0$ if and only if:

$$
H=d_{i}^{2}-2\left(1+n_{i}\right) d_{i}+1+2 \beta b_{i} n_{i}<0
$$

As $\partial^{2} H / \partial d^{2}>0$, we have $H<0$ if and only if $d_{i}$ lies between the two solutions of $H=0$, i.e.

$$
1+n_{i}-\sqrt{n_{i} \Delta_{i}}<d_{i}<1+n_{i}+\sqrt{n_{i} \Delta_{i}}
$$

If $\Delta_{i}<0$, no such solution exists for $d_{i}$ and we must have $L>0$. 


\section{Appendix III, Example 1, Total welfare loss under free trade:}

Assume $m=2, a_{1}=14, a_{2}=3, b_{1}=b_{2}=1, n_{1}=6, n_{2}=9, c_{1}=0, c_{2}=0.5$.

Under autarky, we find $p_{1}^{A}=2=q_{1}^{A}, p_{2}^{A}=0.75, q_{2}^{A}=0.25$. As welfare $S W_{i}=0.5\left(a_{i}-p_{i}\right)^{2} / b_{i}+$ $n_{i} q_{i}\left(p_{i}-c_{i}\right)$, we find $S W_{1}^{A}=0.5 \times 12^{2}+6 \times 2 \times 2=96$, and $S W_{2}^{A}=0.5(3-0.75)^{2}+9 / 16=99 / 32$. So the total welfare $S W_{1}^{A}+S W_{2}^{A}=96+99 / 32=99.1$.

Under free trade, we obtain $p^{T}=13 / 16, q_{1}^{T}=13 / 8, q_{2}^{T}=5 / 8$. Thus we have two countries' welfare $S W_{1}^{T}=0.5 \times(14-13 / 16)^{2}+6 \times(13 / 8)(13 / 16)$, and $S W_{2}^{T}=0.5(3-13 / 16)^{2}+9 \times(5 / 8)(13 / 16-0.5)$. Then we find $S W_{1}^{T}+S W_{2}^{T}=99<S W_{1}^{A}+S W_{2}^{A}$.

Example 2, Total consumer surplus and output fall under free trade:

Let $m=2, a_{1}=9, a_{2}=12, b_{1}=b_{2}=1, n_{1}=1, n_{2}=20, c_{1}=0, c_{2}=21 / 4$.

Under autarky we have $p_{1}^{A}=4.5, p_{2}^{A}=39 / 7$. As $C S_{i}=0.5\left(a_{i}-p_{i}\right)^{2} / b_{i}$, total consumer surplus is $0.5(9-4.5)^{2}+0.5(12-39 / 7)^{2}=30.8$. Under free trade, $p^{T}=21 / 4$ and total consumer surplus is equal to $0.5(9-21 / 4)^{2}+0.5(12-21 / 4)^{2}=29.8<30.8$.

For total output under autarky we have $n_{1} q_{1}^{A}+n_{2} q_{2}^{A}=4.5+45 / 7=10.9$ whereas under free trade $n_{1} q_{1}^{T}=10.5$ and $n_{2} q_{2}^{T}=0$. So the world output is $10.5<10.9$. 